\title{
¿El fin de los diccionarios diferenciales? ¿El principio de los diccionarios integrales?
}

\author{
Raúl Ávila \\ El Colegio de México*
}

\section{EL PROBLEMA}

El concepto de americanismo ha estado marcado ideológicamente desde sus orígenes. Basta con señalar que no existe un país llamado América o Hispanoamérica. La equivalencia, en todo caso, debería hacerse entre europeísmos y americanismos, o entre dos o más países individualmente. Por otra parte, dentro de los diccionarios diferenciales o de regionalismos que se han hecho o planeado, llama la atención que, hasta la fecha, aunque se ha propuesto (Ávila 1998a, Zimmerman 2003, entre otros), no se ha pensado en redactar un diccionario de españolismos, como si no existiera ese tipo de voces. Sólo puedo señalar al respecto que en la última edición del $D R A E$ asoman tímidamente como voces de uso exclusivo en España ordenador y algunos pocos vocablos más.

Me he referido al eurocentrismo o, más específicamente, glosocentrismo español en otras investigaciones (Ávila 1999: 567 ss. y 1998a: 404). Recientemente, el alemán K. Zimmerman -libre de sospechas nacionalistas hispánicas- ha señalado esta situación a propósito de la colección de diccionarios de americanismos dirigida por los también alemanes G. Haensch y R. Werner (2000). Zimmerman considera que en las descripciones del léxico hispanoamericano

* Este artículo fue leído como ponencia en Lingüística 2003, La Habana, con un título diferente. La presente versión, además, ha sido modificada y ampliada para su publicación. 
se refleja una actitud de primacía cultural (y lingüística) de España, de un lado, y de acep[ta]ción de ella en los países hispanoamericanos, del otro. La descripción esencial de la lengua española se basa en la variedad peninsular (y la hacen fundamentalmente los españoles) y las variedades hispanoamericanas se registran como desviaciones de ella, a las que se aplican categorías como americanismo, mejicanismo, venezolanismo, etc. (2003: 74).

Y continúa señalando que los diccionarios contrastivos o diferenciales, dado que sólo buscan la diferenciación con el español de España, merecen el reproche de eurocentrismo. En otras palabras,

El interés unilateral de querer presentar en forma de diccionario sólo los hechos específicos [los ismos], demuestra, sin embargo, desde el punto de vista ideológico, cierta mentalidad colonizada de dependencia de los lingüistas hispanoamericanos [...] se considera más importante y fundamental la variedad peninsular del castellano en los aspectos generales (Zimmerman 2003: 75).

En lo que se refiere a la colección de Haensch y Werner, no obstante la eliminación del concepto de -ismo en favor de diccionarios del español de América frente al español de España, "la orientación global, sin embargo, quedó la misma, sobre todo al [sic] respecto de la contrastividad" (Zimmerman 2003: 76). Coincido con Zimmerman en lo relativo a la orientación. Sin embargo, el cambio de nombre en los nuevos tomos de la colección, implica una nueva posición y supera el problema conceptual de los ismos, al explicitar la comparación de dos dialectos. La solución tiene sentido, como trataré de mostrar más adelante. El problema ideológico, en cambio, se mantiene, ya que el punto de comparación es un solo país: España.

\section{EL REGIONALISMO}

Como he planteado previamente (Ávila 1998: 397, ver también Rona 1969), el concepto de regionalismo se puede formalizar mediante la ecuación

$$
\mathrm{A}(\mathrm{x}) \sim \mathrm{B}(\mathrm{y})
$$

donde A y B son regiones o dialectos diferentes. En A se presenta el fe- 
¿El fin de los diccionarios diferenciales? ¿El principio de los diccionarios integrales?

nómeno $x$, que corresponde a $y$ en B. Por ejemplo, para limitarme al léxico, en la ciudad de México se usa la palabra lentes, y en la ciudad de La Habana, espejuelos, o en Madrid gafas. Las diferencias entre $x$ e $y$ pueden ser de diferentes tipos: connotativas, como en el ejemplo, o denotativas. Así, en México -y en otros países americanos ${ }^{1}$-, el jugo es el líquido que sale de una fruta al exprimirla. Ese líquido en Madrid se 1lama zumo. En México, en cambio, no se bebe "zumo de naranja", pues esa palabra hace referencia al vaporcillo que sale de la cáscara de un cítrico cuando se aprieta. Puede también suceder que $x$ sea un elemento léxico inexistente fuera de una zona, como en el caso de zacahuil, palabra de origen náhuatl que se usa sobre todo la región de la Huasteca, en México, para designar un tamal muy grande del cual se sirven porciones a los comensales ${ }^{2}$.

En principio no parece haber ningún problema teórico para definir el regionalismo, más allá de la descripción de sus diferentes tipos, que pueden ser -además de léxicos- sintácticos, fonológicos o incluso ortográficos (p. ej., México vs Méjico), y pueden relacionarse con cualquiera de las dimensiones de un diasistema. En cambio, cuando se trata de aplicar el planteamiento a la situación real de la lengua surgen conflictos, sobre todo en relación con los americanismos stricto sensu: formas que existen en toda América -en todos los países hispanohablantes- pero no en España (Rabanales 1953, Rona 1969).

Como dije antes, una comparación adecuada es la que se puede establecer entre los elementos de entidades equivalentes, como las que forman los países. Si se procede así, es posible encontrar un buen nú-

1 Jugo se emplea también en Argentina, Chile, Venezuela, Uruguay (tabla 1), y seguramente en otros países. Consecuentemente, zumo podría considerarse un españolismo absoluto. Las relaciones léxico-semánticas pueden ser aún más complejas (véase Ávila 1997).

2 El zacahuil puede tener hasta un metro de largo, e incluye por lo menos dos tipos de carne: de pollo y de cerdo. Estas realidades inexistentes en una región de las dos que se comparan aparecen frecuentemente en los diccionarios de regionalismos, como señala Valadez (2002: 241) a propósito del DECu (2000). La situación es semejante a la que se puede encontrar en dos lenguas distintas. Así, para el término compadre hay un 'vacío' conceptual en inglés, pues en esta lengua no hay una voz equivalente. 
mero de regionalismos, incluso españolismos stricto sensu. He dado varios ejemplos de este tipo -limitados al ámbito nacional o local-en otras investigaciones (Ávila 1997, para las ciudades de México y La Habana; y Ávila 1998a, para México y España), y algo semejante han hecho otros investigadores para México y España (Moreno 1992: 107 ss), o para varios países de la comunidad hispánica (Ueda 1993). Añado ahora algunos otros vocablos que ejemplifican no sólo los españolismos y otros ismos nacionales, sino también las voces que -por su dispersión geográfica- podrían utilizarse para su empleo en el ámbito del español internacional. Para esto comparo en la tabla 1 la variación léxica en seis países (en orden alfabético) . $^{3}$

Como se puede advertir, frente a las voces de nivel internacional, piloto es un argentinismo por impermeable; peineta, un chilenismo (frente a peine); calle, un españolismo (cuadra en los demás países); recámara, un mexicanismo (frente a dormitorio); guinche, un uruguayismo (frente a grúa); y guindar, un venezolanismo (frente al término colgar). Además, como es de esperarse, puede haber diferente distribución geográfica de los vocablos, como en el caso de alcaucil, que es argentinismo y uruguayismo, frente a alcachofa; o de papaya, de uso más extendido, frente al argentinismo mamón o el venezolanismo lechosa. También pueden darse casos de variación léxica en todos los países, como en el ejemplo de botamanga (Argentina), basta (Chile), vuelta (España), valenciana (México), dobladillo (Uruguay) y ruedo (Venezuela).

3 Tomo estos datos de Molero (2003). El autor hace comparaciones homogéneas, pero no puede evitar el poner a España en la primera columna, lo que implica que se trata de decidir con respecto a ese país. El título de la obra también muestra un sesgo ideológico: El español de España y el español de América. Vocabulario comparado. Tengo algunas dudas sobre la validez de los datos; sin embargo, estas consideraciones están fuera de los propósitos que persigo en esta investigación. En todo caso, las voces son suficientes para ilustrar mis planteamientos. 


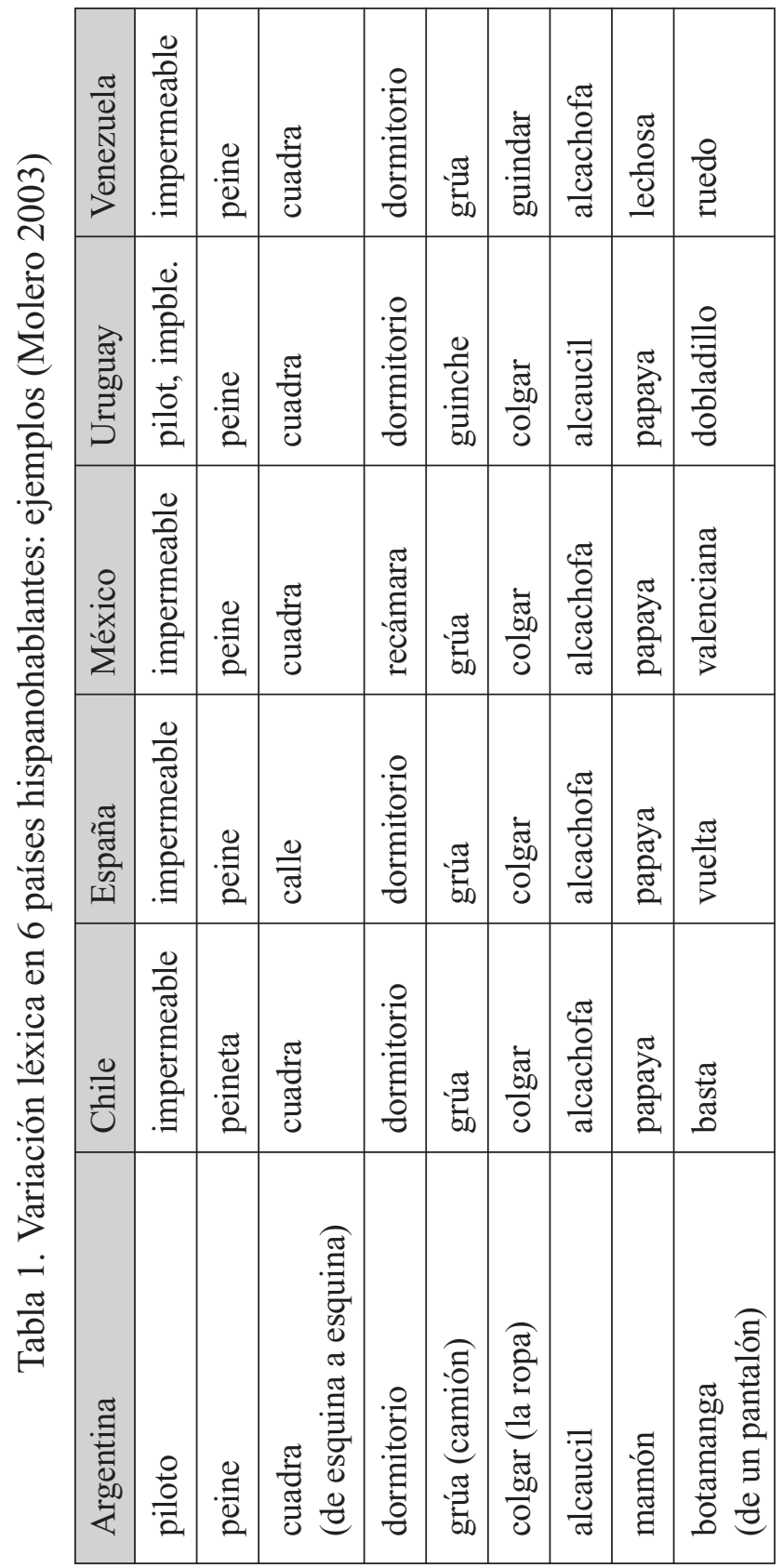




\section{DICCIONARIOS DIFERENCIALES E INTEGRALES}

Los diccionarios diferenciales, como es evidente -y así lo señalan Haensch y Werner- sólo apelan a un público especializado: lingüistas, filólogos, traductores y algunos viajeros cultos ( $D E C u$ : xviii y ss.) que, inevitablemente, forman un grupo muy limitado. Además, algunas voces rebasan las fronteras de los países que se comparan. Como ha señalado Valadez (2002: 242), en el DECu se incluye un buen número de términos que también se emplean en México, en el mismo sentido, como zapote, guacamaya, danzón, desconchinflar, huacal o elevador. Habría que añadir a esto que tanto en el $D E C u$ como en el $D E A r$ hay vocablos que designan realidades inexistentes en España (o en otros países) sobre todo referentes a plantas y animales, lo que, en alguna medida, implica la inclusión de tecnicismos.

Otra característica de los diccionarios diferenciales es que muchas de las voces que incluyen son del español hablado, de uso coloquial -la marca más empleada en el DECu (Valadez 2002: 240)- o grosero, referidas, por ejemplo, a las pars pudendi. Estas observaciones, sobre todo las relacionadas con el uso coloquial, pueden extenderse también al más reciente diccionario de mexicanismos ( $D B M e x)$. En una muestra aleatoria encontré que cerca del 50 por ciento de las entradas eran de uso coloquial -aunque no siempre lo indicaba así el autor ${ }^{4}$, y un 22 por ciento correspondían a referentes característicos de la realidad natural de México -sobre todo plantas y animales- y a gentilicios regionales -soconusqueño, silaoense y otros. Además, muchas de las voces restantes no son necesariamente mexicanismos stricto sensu, o por lo menos son discutibles en cuanto tales, pues se usan en España o en otros países de América, como listón (DRAE, s.v.), limosnero (se usa “en Andalucía y América”, DRAE, s. v.), morgue (v. DRAE, s. v.) o ro$\operatorname{tar}(D R A E, \mathrm{~s} . \mathrm{v}$.$) .$

4 En la reseña que hizo al DBEMex, Lara (2002) señala, además, otras imprecisiones de la obra a las que no me referiré porque salen de los propósitos de esta investigación. Este diccionario, como los de regionalismos de otros países, toma como referencia el español de España para delimitar los mexicanismos. 
¿El fin de los diccionarios diferenciales? ¿El principio de los diccionarios integrales?

Teóricamente, la comparación de vocablos de dos países tiene sentido, como señalé previamente, bajo la condición de que no se pretenda la exclusividad nacional de todas y cada una de las voces. Los problemas son otros. Como he dicho antes, uno de ellos consiste en hacer siempre las comparaciones entre un país hispanoamericano y España, y no entre dos países hispanoamericanos. Las definiciones, además, se hacen en el español de España, para lectores españoles. Como dice la mexicana Valadez en su reseña del $D E C u$, "la constante comparación con el español de España me estorba un poco, especialmente cuando los definientes corresponden al uso de España y no al de México, e incluso, a veces tampoco al de Cuba" (2003: 242, cursiva mía).

Todo esto muestra lo evidente: un diccionario diferencial o de ismos no sirve para hablar, no es autosuficiente. Allí se incluye lo diferente, lo raro, lo periférico ${ }^{5}$. Ese tipo de léxico, que he llamado marcado, se escucha muy poco en el habla culta o en la que se transmite por los medios de difusión masiva, como he señalado en otro lugar (Ávila 1998b). Añado ahora que en los programas deportivos que se transmiten en la televisión mexicana -narraciones espontáneas- los ismos apenas llegan, en el nivel de vocablos, al 2,8 por ciento. Si se consideran las apariciones reales de esos vocablos en la cadena hablada, el porcentaje baja hasta un 0,68 por ciento - una cantidad absolutamente trivial ${ }^{6}$.

Frente a los diccionarios diferenciales se plantea la necesidad de redactar diccionarios integrales o nacionales. Las razones son varias. La primera es lingüística. Como he señalado en otra parte (Ávila 1997), hay relaciones léxicosemánticas que se establecen en cada dialecto como totalidad, entre las voces coexistentes. Estas relaciones sólo pueden ser tomadas en cuenta cuando se definen los vocablos del dialecto en su

5 Ese tipo de diccionario hace recordar la novela 1984, que publicó George Orwell hace ya bastantes años, en 1949: "la finalidad de la neolengua es limitar el alcance del pensamiento, estrechar el radio de acción de la mente [...] Cada año habrá menos palabras y el radio de acción de la conciencia será cada vez más pequeño" (trad. de Rafael Vázquez Zamora, México, Planeta, 2003, 6 reimpr., pp. 59-60).

6 Tomo los datos de mi investigación sobre el lenguaje deportivo, que está en proceso de redacción. 
conjunto. La única forma de considerarlas es a partir de la intuición de los lexicógrafos nativos. En Chile, por ejemplo, no sólo se usa la voz peineta (tabla 1) sino también peine -lo que no consigna Molero (2003), porque no se propone recoger hechos de autorregulación (Ávila 1997) ${ }^{7}$. La diferencia estriba en que en Chile la peineta es pequeña y el peine, grande. En México, en cambio, el peine es pequeño y la peineta, grande.

La segunda razón tiene que ver con hechos ideológicos. Los diccionarios diferenciales -insisto- no sirven para hablar, pues no incluyen el léxico fundamental de la lengua. No hay amor, consideración, pensamiento, desacuerdo; no se sabe qué es discutir, imaginar o soñar. Esas palabras se definen en los diccionarios hechos en otro lugar, por personas que no necesariamente coinciden con los planteamientos que se podrían hacer desde los países hispanoamericanos. Por otra parte, un diccionario de ese tipo, como el $D R A E$, que pretende ser del español general, termina por ser un diccionario nacional con la inclusión de algunos ismos americanos, a los que se añaden un buen número de regionalismos de España -lo que los hace equivalentes, inadecuadamente, a los primeros: un asturianismo, p. ej., es igual a un mexicanismo. Estos conflictos no se presentan en un diccionario nacional o integral, como el Diccionario del español usual en México (DEUM), que incluye las voces que se usan en ese país, sin indicaciones geográficas.

Hay una clase relativamente nueva de diccionarios integrales, los escolares o pedagógicos. Este tipo de obras es muy importante como apoyo a la formación de los estudiantes, y la ampliación de su universo conceptual. Esos diccionarios han sido redactados casi en su totalidad en España, con la excepción del Diccionario inicial del español de México (DIME), que es mexicano ${ }^{8}$, y del Diccionario básico escolar,

7 Confirmé esta diferencia cuando pregunté a un amigo chileno si conocía la voz peine. Su respuesta no me sorprendió. He encontrado este tipo de relaciones en otros lugares, como La Habana (Ávila 1997).

8 El DIME contiene más de 13000 entradas, con más de 22000 acepciones, cada una con un ejemplo de uso. La nomenclatura se formó a partir del léxico que se obtuvo de textos de estudiantes de primaria de todo México (cerca de medio millón de palabras) 
¿El fin de los diccionarios diferenciales? ¿El principio de los diccionarios integrales?

redactado en Santiago de Cuba (DBES) aunque, de acuerdo con el título, parece del español general ${ }^{9}$. Un lector de cualquier país hispanoamericano podría descubrir en los diccionarios pedagógicos españoles problemas semejantes a los que he comentado en relación con el $D R A E$, o incluso mayores. Esas obras describen el léxico del español de España, pero - de nuevo- a los autores no les parece necesario mencionarlo. Véanse, por ejemplo, la investigación de Martínez Marín (1992). Lo que él destaca en relación con el título de ese tipo de obras es que "parece haberse generalizado el término escolar" (1992: 58) para nombrarlos. En cambio, no le da importancia al hecho de que en todos los títulos se dice que son diccionarios de la "lengua española", o simplemente "de la lengua", sin mencionar que se trata de la lengua española de España. Eso equivaldría a que el Diccionario inicial del español de México tuviera como título simplemente Diccionario inicial del español o ... de la lengua, y que se distribuyera en España con ese nombre.

y del que se recogió en textos del nivel secundario; se contó además con el apoyo de los materiales del DEUM(dos millones de palabras). Todas y cada una de las acepciones y los ejemplos del DIME fueron redactados de manera original. Actualmente está en prensa la $2^{\mathrm{a}}$ ed., corr. y aum.

9 El DBEs, según se indica en el prólogo, "se redactó en el último lustro" (p. viii), y "posee más de 8000 entradas y alrededor de 20000 acepciones" (p. ix). Se concibe como del español general, aunque con "la presencia de los vocablos preferidos por los hablantes cubanos y las variantes léxicas presentes en el español de Cuba, aunque no sean considerados regionalismos" (p. viii). Sin embargo, hay bastantes contradicciones; p. ej., bajo la voz colectivo, se indica la ac. 3. como cubana: "En Cuba, grupo de personas..." En cambio timón (que corresponde al término más general volante, $D R A E$, s. v., no incluido en $D B E s$ ), no se indica como cubanismo. Lo mismo sucede con azocar, marcado como regionalismo "cub. Causar molestias...", murumaca "En Cuba, mueca o gesto...". Frente a estos vocablos, molote, ferromozo o espaldar, entre otros, aparecen sin marca, aunque no son del español general. Aparte de lo anterior, la obra tiene un buen número de pistas perdidas. Por ejemplo, en huevo se incluyen los definientes "útero" y "cigoto", que no están en la nomenclatura; lo mismo ocurre con "protón" y "neutrón" (bajo la voz átomo); "profesa" (bajo la voz médico) o "perico" y "pericón" (bajo la voz abanico, sinónimos de esta). Los redactores tampoco parecen haber definido un criterio para la inclusión de gentilicios: aparecen francés, pero no sueco; dominicano, pero no mexicano (aunque incluyen azteca); santiaguero (de Santiago de Cuba), pero no el más conocido guantanamero. 
En otro trabajo más reciente sobre la lexicografía escolar, "desde sus orígenes hasta su consolidación" (Hernández 2003), el autor describe los avatares de los diccionarios didácticos, sus problemas, sus características y sus posibilidades. Los países hispanoamericanos sólo son mencionados en relación con la ausencia de léxico dialectal -sobre todo de las "áreas americanas" (2003: 8, n.)-; o para comentar que en uno de los diccionarios pedagógicos "se incluye un buen número de americanismos, extranjerismos y voces y expresiones de argot, pero sin indicar cuáles de ellas cuentan con el respaldo académico" (2003: 14). El autor considera conveniente que hubiera "más crítica lexicográfica seria en los países hispanohablantes, como ya ha recomendado G. Haensch" (2003: 18), pues de esta manera se podrían mejorar los diccionarios pedagógicos -los españoles, claro. De paso, el autor no parece tener conciencia de algunos posibles españolismos -o tecnicismos-, como antruejo ('conjunto de los tres días de carnestolendas') y driza ('cuerda o cabo'), que cita para indicar algunos problemas en sus definiciones (2003: 16). Sin embargo, Hernández señala -quizá pensando en Andalucía o Canarias, pero quizá también en las zonas dialectales de América-, que es necesario hacer

diccionarios escolares integrales para cada área lingüística diferenciada: un diccionario escolar que registre, defina y caracterice lo general y lo particular es la única manera de ofrecer a los estudiantes una perspectiva adecuada de la realidad de la lengua tal y como se actualiza en cada zona dialectal (2003: 24).

Habría que tomarle la palabra en cada uno de los países hispanoamericanos.

\section{CONCLUSIONES}

Las razones que he expuesto -a las que se podrían añadir varias más- muestran la necesidad de redactar diccionarios nacionales o integrales en los países hispanoamericanos, obras autosuficientes en las que esté el sistema léxico completo, los ismos y las voces de uso general. Se ha señalado -y cualquiera puede constatarlo incluso en su propia casa si escucha programas de radio y televisión de alcance internacional- que 
¿El fin de los diccionarios diferenciales? ¿El principio de los diccionarios integrales?

el español es una lengua policéntrica (Zimmerman 2003: 74), con diferentes normas, sobre todo nacionales. Una investigación reciente ha mostrado incluso que entre los dialectos hay diferencias semánticas semejantes a las que se dan entre lenguas distintas (Ávila 1997). Es necesario reconocer lo evidente y proceder en consecuencia. Los diccionarios nacionales serían una confirmación de ese hecho, bajo la condición de que incluyan definiciones originales, que respondan a los valores semánticos y la cultura de cada país. Ya hay algunos con estas características, tanto para el lector general (DEUM) como para los estudiantes de educación básica $(D I M E)^{10}$. Esos repertorios léxicos podrían servir de base para la redacción del diccionario internacional de la lengua española. Los diccionarios diferenciales, por supuesto, son también un sustento para la redacción de los nacionales, y así lo planteaba Menéndez Pidal en "El diccionario ideal", aunque a veces se olvidaba de ubicar adecuadamente a los países hispanoamericanos en sus planteamientos (1961).

Los nuevos diccionarios diferenciales -el DECu y el DEAr-están hechos con una metodología muy rigurosa, e implican un trabajo arduo y fructífero. Sin embargo, la etapa de los diccionarios diferenciales no se puede considerar concluida, como sugería Zimmerman. Falta sobre todo uno de ellos: el del español de España ${ }^{11}$. En cuanto a los dicciona-

10 El $D B E s$, aunque redactado en Cuba por cubanos, no puede considerarse estrictamente un diccionario nacional, de acuerdo con lo que la directora indica en el prólogo (v. nota anterior). No obstante, puede decirse que es una obra encaminada en esa ruta, y merece un reconocimiento por el esfuerzo y el resultado que se obtuvo en tan poco tiempo. Esperemos que, además de redactar de manera más sencilla algunas de las definiciones - dados los lectores a los cuales va dirigida: del segundo ciclo de primaria en adelante (según correo electrónico enviado por L. Ruiz Miyares, del equipo de cómputo del $D B E S$ ) - , en la segunda edición los autores resuelvan algunos de los problemas que he señalado previamente (v. nota anterior). Por otra parte, convendría que se declarara en alguna medida la posición ideológica de la obra (como se hace, p. ej., en el DIME, donde se proponen igualdad de sexos, conciencia ecológica, etc.), para que el lector no se sorprenda con varios de los ejemplos.

11 La comparación puede hacerse con respecto a uno o a varios países. Si se consideran los que he mencionado en la tabla 1, pueden añadirse los siguientes españolismos: patata (frente a papa), solomillo (lomo), melocotón (durazno), albornoz (bata, bata de 
rios integrales, habría que aprovechar la oportunidad que ofrece ese espacio tan amplio de la lexicografía y continuar con su redacción. Esos nuevos diccionarios, libres de las ataduras académicas, podrían ser una aportación de gran trascendencia para la lexicografía de la lengua española. Entre otras posibilidades, ofrecerían la de poder comparar de manera homogénea el léxico diferencial y el compartido. Hay quienes, desde una posición eurocéntrica propia de otras épocas, parecen no ubicar adecuadamente las voces de los países y las regiones hispánicas de América. Por eso es necesario que redactemos diccionarios nacionales. Así no olvidaremos nuestras palabras -las que compartimos, que son la mayoría, y las que nos identifican dentro del ámbito nacional. Esos diccionarios deben ser la base que sustente el español internacional. Seguramente permitirán constatar, de nuevo, la unidad esencial de nuestra lengua.

\section{REFERENCIAS BIBLIOGRÁFICAS}

ÁvILA, R. (1997): "Variación léxica: connotación, denotación, autorregulación", Anuario de Letras, XXXV, pp. 77-102. Véase también en http://www.colmex.mx/personal/cell/ravila/index.htm.

Ávila, R. (1998a): "Españolismos y mexicanismos: hacia un diccionario internacional de la lengua española", NRFH, XLVI, pp. 395-406. Véase también en http://www.colmex.mx/per-sonal/cell/ravila/index.htm.

ÁvilA, R. (1998b): “Televisión internacional, lengua internacional”, en $L a$ lengua española y los medios de comunicación. Primer Congreso Internacional de la Lengua Española. Zacatecas, México, 1997, México, SEP-Instituto Cervantes-Siglo XXI, II, pp. 911-930. Véase también en http://www.colmex.mx/personal/cell/ravila/index.htm.

ÁviLA, R. (1999): "La comunidad hispánica y la lengua cien años después [de 1898]", Estudios Sociológicos, XVII, 50, pp. 559-579. Véase también en http://www.colmex.mx/ personal/cell/ravila/ index.htm.

ÁvilA, R. (2003): "Diccionarios locales, nacionales, internacionales", RILI, 1/1, pp. 51-66.

baño), salpicadero (tablero de un coche), hucha (alcancía), chincheta (chinche), cuentagotas (gotero), campo de juego (cancha), y teléfono móvil (celular). 
¿El fin de los diccionarios diferenciales? ¿El principio de los diccionarios integrales?

DBEs (2003): Eloína Miyares Bermúdez (dir.), Diccionario básico escolar, Santiago de Cuba, Ediciones Lingüística Aplicada [abril]. DBMex (2001): Guido Gómez de Silva, Diccionario breve de mexicanismos, México, Academia Mexicana-Fondo de Cultura Económica. DEArg (2000): Günther Haensch y Reinhold Werner (dirs.), Claudio Chuchuy (coord.): Diccionario del español de Argentina. Español de Argentina-Español de España, Madrid, Gredos.

DECu (2000): Günther Haensch y Reinhold Werner (dirs.), Gisela Cárdenas Molina, Antonia María Tristá Pérez y Reinhold Werner (coords.): Diccionario del español de Cuba. Español de Cuba-Español de España, Madrid, Gredos.

DEUM(1998): Luis Fernando Lara (dir.): Diccionario del español usual en México, México, El Colegio de México.

DIME (2003): Raúl Ávila, con la colab. de Gerardo Aguilar: DIME. Diccionario inicial del español de México, Trillas, México [enero]. DRAE (200122): Real Academia Española, Diccionario de la lengua española, Madrid, Espasa.

Hernández, H. (2003): “La lexicografía escolar del español: desde sus orígenes hasta su consolidación", RILI, 1/1, 7-26.

LARA, L. F. (2002): Reseña del DBMex, NRFH, L, pp. 228-237.

MARTíneZ MARíN, J. (1992): “Los diccionarios escolares del español: lo que son y lo que deberían ser", en I. Ahumada (ed.), Lecciones del I Seminario de Lexicografía Hispánica, Jaén, Casa Editora El Estudiante, pp. 53-70.

MenÉndez Pidal, Ramón (1970² [1961]): “El diccionario ideal”, en sus Estudios de lingüística, Madrid, Espasa Calpe, pp. 95-147.

Moreno de Alba, José G. (1992): Diferencias léxicas entre España y América, Madrid, Mapfre.

NDEAArg (1993): G. Haensch y R. Werner (dirs.), Claudio Chuchuy y Laura Hlavacka de Bouzo (coords.): Nuevo diccionario de americanismos, III: Nuevo diccionario de argentinismos, Bogotá, Instituto Caro y Cuervo.

NDEACol(1993): G. Haensch y R. Werner (dirs.): Nuevo diccionario de americanismos, I: Nuevo diccionario de colombianismos, Bogotá, Instituto Caro y Cuervo.

NDEAUru (1993): G. Haensch y R. Werner (dirs.), Úrsula Kühl de Mones (dir.): Nuevo diccionario de americanismos, III: Nuevo diccionario de uruguayismos, Bogotá, Instituto Caro y Cuervo. 
Rabanales, Ambrosio (1953): Introducción al estudio del español de Chile, Santiago, Instituto de Filología de la Universidad de Chile.

Rona, J. P. (1969): “¿Qué es un americanismo?”, en El simposio de México, enero de 1968. Actas, informes y comunicaciones, México, UNAM, pp. 135-148.

UEDA, H. y T. TAKAGAKI (coords.) (1993): Variación léxica del español en el mundo. Mapas y estadísticas, Tokio, Universidad de Tokio.

VALADEZ, C. D. (2002): Reseña del DECu y del DEAr, NRFH, L, pp. 238245.

ZIMMERMAN, K. (2003): "El fin de los diccionarios de americanismos. La situación de la lexicografía del español de América después de la publicación de los Diccionarios contrastivos del español de América", RILI, 1/ 1, pp. 71-83. 